\title{
A recent update of the diagnostic methods for tuberculosis and their applicability in Indonesia: a narrative review
}

Tri Nugraha Susilawati, ${ }^{1}$ Riska Larasati ${ }^{2}$

pISSN: 0853-1773 • elSSN: 2252-8083 https://doi.org/10.13181/mji.v28i3.2589 Med J Indones. 2019;28:284-91

Received: January 19, 2018

Accepted: June 18, 2019

\section{Authors' affiliations:}

${ }^{1}$ Department of Microbiology, Faculty of Medicine, Universitas Sebelas Maret, Surakarta, Indonesia, ${ }^{2}$ Faculty of

Medicine, Universitas Sebelas Maret,

Surakarta, Indonesia

Corresponding author:

Tri Nugraha Susilawati

Department of Microbiology, Faculty of Medicine, Universitas Sebelas

Maret, Jalan IR Sutami 36 A, Kentingan,

Surakarta 57126, Indonesia

Tel/Fax: +62-271-632489

E-mail: tri.susilawati@staff.uns.ac.id

\begin{abstract}
Tuberculosis (TB) is a major global problem, especially with the high prevalence of HIV-TB co-infection. Delayed diagnosis and continual transmission contribute to high mortality in Indonesia, which has the third highest incidence of TB in the world, after China and India. Therefore, early diagnosis is needed to reduce the number of cases and to administer therapy to prevent the transmission of bacteria. The diagnosis of TB remains a challenge in clinical practice due to poor sensitivity and the requirement of skilled staff in microscopic tests, the slow growth Mycobacterium in culture, and the low number of bacilli present in extrapulmonary TB. Despite being the golden standard for TB diagnosis, cultures require 2-8 weeks to grow. Other methods for diagnosing TB include interferon-gamma release assays and serologic tests such as the tuberculin skin test. Recently, the World Health Organization recommended the GeneXpert MTB/RIF assay for diagnosing TB. This review presents the current state of TB epidemiology and various methods for TB diagnosis. In particular, the paper provides an in-depth discussion about the GeneXpert MTB/RIF assay that has been made available recently in selected tertiary hospitals in Indonesia.
\end{abstract}

KEYWORDS diagnosis, infection, tuberculosis
Tuberculosis (TB) imposes a significant disease burden on society due to its high morbidity and mortality. In 2017, there were about 10 million new cases. There were 1.3 million deaths among human immunodeficiency virus (HIV)-negative people and 300,000 deaths among HIV-positive people attributed to TB globally. Among the global major causes of death in 2016, TB became the $10^{\text {th }}$ greatest cause of death after ischemic heart disease, stroke, chronic obstructive pulmonary disease, lower respiratory tract infections, Alzheimer's disease and other dementias, tracheal, bronchial and lung cancers, diabetes mellitus, road injuries, and diarrheal diseases. ${ }^{1}$

Along with the growing HIV epidemic, TB affects all countries. Two-thirds of all TB cases are found in only eight countries: India (27\%), China (9\%), Indonesia (8\%), Philippines (6\%), Pakistan (5\%), Nigeria (4\%), Bangladesh (4\%), and South Africa (3\%). Indonesia ranks third in the world in the number of TB cases, after China and India. Of the 264 million people in Indonesia (in 2017), the total TB incidence was 842,000 and the total HIV-TB co-infection incidence was 36,000. The mortality rate for that year was 107,000 deaths among HIV-negative TB cases and 9,400 deaths among cases of HIV-TB co-infection. ${ }^{1}$ The disease poses a significant economic impact in the country, as $75 \%$ of TB survivors are from the productive age group (15-50 years old), who often become unable to work and also lower the productivity of other family members or carers. ${ }^{2}$ A previous study showed that the economic impact 
of TB in Indonesia is extremely high with a total of $\$ 6.9$ billion US dollars in 2015. This was attributed to the loss of productivity due to premature deaths and illnesses, as well as medical and non-medical costs. ${ }^{3}$

The mortality rate of TB remains high partially due to delayed diagnoses and uncontrolled transmission. Rapid detection of TB is needed to start anti-TB treatment so that further transmission can be prevented. The commonly used methods for detecting Mycobacterium tuberculosis include microscopy and culturing. Other methods to diagnose TB include the tuberculin skin test (TST), interferon-gamma release assay (IGRA), and nucleic acid amplification test (NAAT).

The TST is a delayed-type hypersensitivity reaction that occurs in TB-infected individuals. The limitations of TST include antigenic cross-reactivity, low sensitivity, low specificity, and the potential for false-positive results. IGRA examines the interferongamma (IFN- $\gamma$ ) response to TB antigens, including early secretory antigenic target-6 (ESAT-6), cultures filtered protein-10 (CFP-10), and TB7. Due to its higher specificity compared to TST, IGRA is particularly useful for diagnosing TB in immunocompromized persons and patients with inflammatory diseases. ${ }^{4}$ GeneXpert MTB/RIF (Cepheid, Sunnyvale USA) is a recommended molecular assay to detect $M$. tuberculosis that provides additional advantages compared to conventional methods. The assay uses quantitative real-time polymerase chain reaction (qRT-PCR) to detect both $M$. tuberculosis and rifampicin resistance within 2 hours..$^{5-7}$ This review discusses the basic concept of TB, the different types of diagnostic methods, and the specimens for TB diagnosis.

\section{The microbe and pathogenesis of TB}

TB is an infectious disease caused by the Mycobacterium tuberculosis complex (MTBC). ${ }^{8}$ Besides M. tuberculosis, MTBC consists of other related species such as $M$. africanum, $M$. microti, and M. bovis. ${ }^{9}$ The Mycobacterium genus is categorized as acid-fast bacilli (AFB) due to its resistance to acidalcohol decolorization.

Based on the site infected, TB can be divided into pulmonary and extrapulmonary TB (EPTB). The infection is initiated by the aerosol inhalation of $M$. tuberculosis. After inhalation, the droplet nucleus is deposited into the bronchial tree which attach to bronchiole or alveoli. ${ }^{10,11}$ Initial TB infection is characterized by an innate immune response involving inflammatory cells. The adaptive immune response is characterized by the dissemination of the bacteria in lymph nodes where antigen presentation in the dendritic cells leads to $T$ cell activation and expansion into the lungs. The infiltration of $\mathrm{T}$ cells, B cells, macrophages, and leucocytes triggers a formation of granuloma that contains the $M$. tuberculosis (Figure 1). ${ }^{12}$ The bacteria entering human lungs are mostly digested by alveolar macrophages, but some of the bacteria multiply inside the macrophages and are later released after the macrophages are dead. The living macrophages (containing $M$. tuberculosis) can spread the bacteria via the lymphatic system or via the bloodstream into the tissues and organs; leading to EPTB. ${ }^{10}$ Around $15-20 \%$ of EPTB affects the lymph nodes, meninges, kidneys, the spine, and bones. EPTB has an atypical clinical presentation that is often stimulated by neoplasia or inflammation. ${ }^{13}$

TB transmission occurs when an infected person spreads droplets into the air. The main symptoms of TB in adults and children include a persistent cough, low-grade fever, lethargy, loss of weight, and night sweats. TB transmission is determined by a number of factors. First, the level of infectivity or disease severity; which is assessed using sputum microscopy and chest radiology. Second, the contact history with TB patients and the duration of the contact; the more frequent and the longer the contact between a healthy individual and an infected person will increase the chance of TB infection. Third, the space of exposure; where small, enclosed spaces with inadequate ventilation are conducive to transmission. Fourth, the infectivity of bacterial strain; some strains of $M$. tuberculosis are more infectious than the others. For example, the extrapulmonary strain has higher infectivity than the pulmonary strain, as it can harm the macrophages more effectively. ${ }^{11,14,15}$

TB infection in a susceptible individual is indicated by a positive AFB smear or in radiographic results. The indicative radiology findings include hilar lymphadenopathy, lobar or segmental consolidation, pleural effusion, miliary lesions, atelectasis, infiltrate calcification, and tuberculoma. A major challenge for TB diagnosis using conventional methods is their poor sensitivity in detecting $M$. tuberculosis $(20-80 \%) .{ }^{16-18}$ The diagnosis of EPTB is even more 
Figure 1. Pathogenesis of tuberculosis

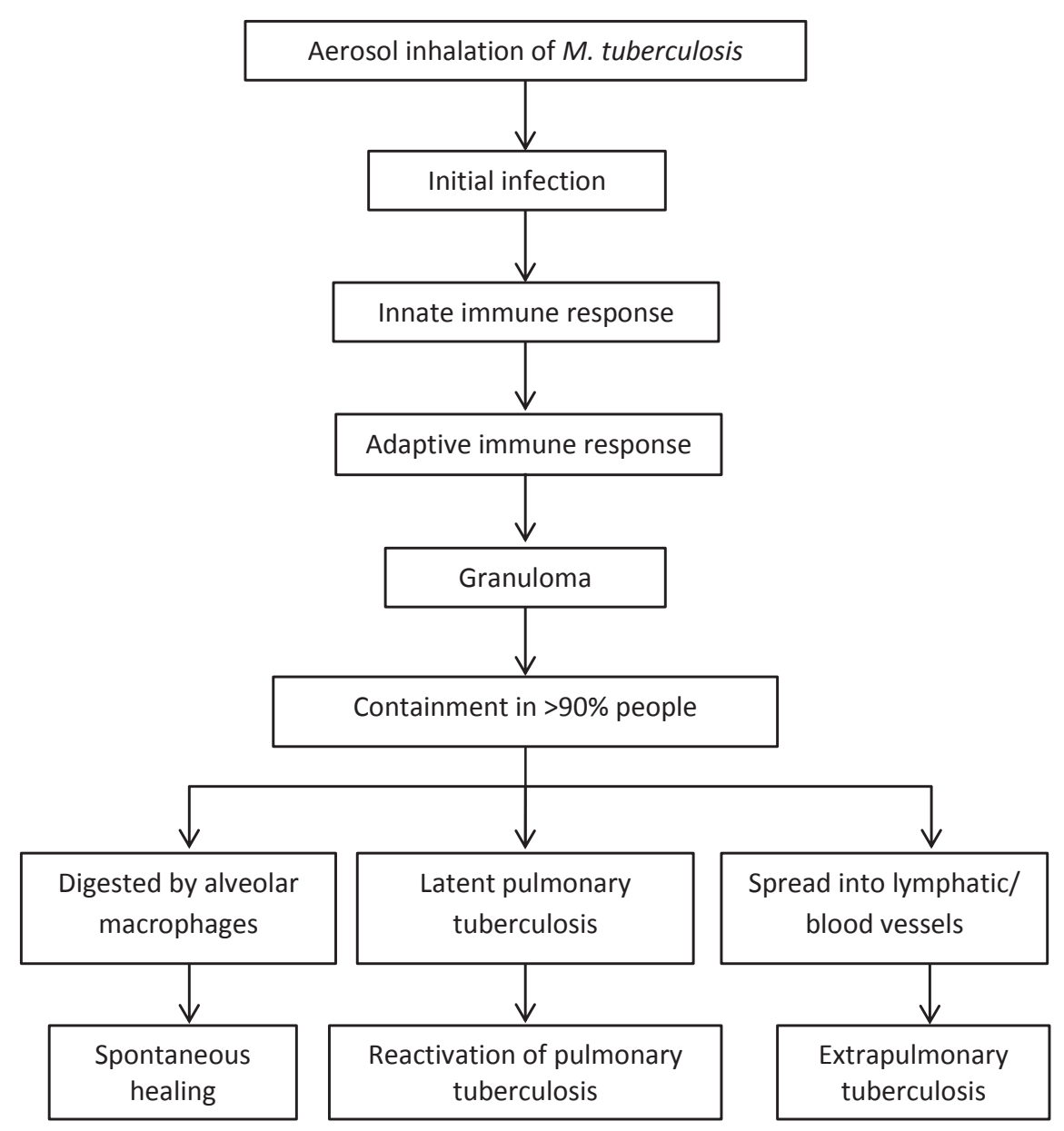

challenging due to the low number of bacteria in the specimens taken from infected sites. ${ }^{19}$ Culturing is the standard reference to diagnose TB, but this requires 2-8 weeks. $^{20,21}$ Further details on TB diagnosis and the challenges are discussed below.

\section{Diagnosis: methods and samples}

Diagnosis appraisal of TB includes medical history, physical examination, and further examination to identify $M$. tuberculosis infection. In pulmonary TB, the etiological diagnosis is based on the results of microscopic tests, culturing, and other tests (preferably tests that provide rapid results). If the laboratory results come back negative, clinical diagnosis and further tests should be performed. In extrapulmonary TB, the diagnosis is determined through clinical examination as well as bacteriological and/or histopathology results from the affected site. ${ }^{2}$

The first and the most common diagnostic method for TB infection is AFB staining with carbol fuchsin (Ziehl Neelsen and Kinyoun-Gabbet methods) and fluorochrome (auramine-rhodamine stains). The second method is the cultivation of specimens using a specific medium to grow out the bacilli. The third method is a serological assay with TST or Mantoux test. The fourth method for TB detection is IGRA, and the last method is NAAT with GeneXpert MTB/RIF assay (GeneXpert). ${ }^{4}$

The results of the AFB staining are interpreted in accordance with the classification criteria established by the World Health Organization (WHO). This diagnostic method is inexpensive and rapid. However, it has poor sensitivity ( $70 \%)$ and is dependent on the skill of the personnel performing the test.7,10 If the result of the AFB staining is negative but the clinical suspicion is high, culturing should be performed to test for $M$. tuberculosis. ${ }^{4,22}$

Culturing is a golden standard in the diagnosis of $M$. tuberculosis infection. ${ }^{4,11}$ The specimens used to grow the bacteria is taken from the site or organ with suspected TB infection, such as sputum, urine, cerebrospinal fluid (CSF), pleural fluid, pus, and tissue biopsy. Sputum is collected in various ways. For example, by spontaneous coughing, coughing induction using saline inhalation, bronchoscopy, and 
gastric aspiration. ${ }^{10}$ The culturing of bacteria is an important test of TB as it can also be used to analyze drug susceptibility and increase the detection of smear-negative AFB. It can be performed in solid media such as Lowenstein Jensen (LJ), Ogawa, Middlebrook $7 \mathrm{H} 10$ and $7 \mathrm{H} 11$ or liquid media such as Bactec $^{\mathrm{TM}}$ mycobacteria growth indicator tube (MGIT $\left.^{\text {TM }}\right) 960$ System, Bactec ${ }^{\text {TM }} 9000 \mathrm{MB}$, etc. ${ }^{17}$

The specimens intended for culturing is processed through digestion and decontamination with $\mathrm{N}$-acetyl-L-cysteine and sodium hydroxide (NALC/NaOH) and centrifugation of 3,500g for 15 min. Then, the specimen is resuspended in $1 \mathrm{ml}$ of sterile buffer phosphate $(\mathrm{pH} \mathrm{6.8)}$ before being placed into a solid medium (such as LJ medium) with a specimen volume of $0.2 \mathrm{ml}$ or liquid media such as MB/BacT (bioMérieux, Marcy l'Etoile, France) and Bactec $^{\text {TM }}$ MGIT $^{\text {TM }} 960$ with a specimen volume of 0.5 $\mathrm{ml}$. Lastly, the specimen is incubated at $37^{\circ} \mathrm{C}$ for 6 weeks. ${ }^{17,23}$ Culturing of $M$. tuberculosis is effective at 10-10 ${ }^{2} \mathrm{CFU} / \mathrm{ml}$ and has a higher sensitivity than AFB staining. However, the growth of $M$. tuberculosis in culture is very slow. Thus, the culture may require up to 8 weeks of incubation to grow. ${ }^{24}$ In addition, appropriate laboratory infrastructure and skilled staff are needed. ${ }^{18,22,25}$

TST uses tuberculin is a purified protein derivate that can induce a delayed-type hypersensitivity after intradermal injection. A positive reaction is indicated by a $5 \mathrm{~mm}$ induration in immunocompromized patients, a $10 \mathrm{~mm}$ induration in immunocompetent children and in adults who have never received any vaccination, and $15 \mathrm{~mm}$ in those who have been vaccinated. The sensitivity and specificity of the tuberculin skin test among these groups are: $100 \%$ and $90.3 \%, 97.2 \%$ and $91.9 \%, 86.1 \%$ and $94.2 \%$, respectively. There is a possibility of cross-reaction with other antigens from the Bacilli Calmette-Guérin (BCG) vaccine and environmental mycobacteria., ${ }^{4,11}$ It has been reported that the test can generate falsepositive results in $86.1 \%$ of individuals who have been previously vaccinated with BCG. ${ }^{26}$ If the TST result is positive in BCG-vaccinated individuals, further confirmatory tests should be performed.

IGRA is a diagnostic method that involves measuring the immune response of IFN- $\gamma$ to TB antigens, including ESAT-6, CFP-10, and TB7.7. Those antigens were encoded by the gene in a region of difference 1 of the $M$. tuberculosis complex. Because this method detects the immune response to TB antigens located in specific regions of the bacterial gene, it has higher sensitivity and specificity than TST. 4,11

The IGRA method is based on the enzyme-linked immunosorbent assay (ELISA) and the enzymelinked immunospot (ELISpot) assay. An example of the ELISA-based kit is QuantiFERON®-TB Gold InTube (Cellestis Ltd., Carnegie, Australia) whereas the T-SPOT®.TBTM test (Oxford Immunotec Inc., Abingdon, UK) is based on the ELISpot assay. ${ }^{27}$ The specificity of IGRA is higher than TST, thus IGRA is very useful for the screening of TB, TB-HIV co-infection, and TB in immunocompromized patients. A limitation of IGRA is the presence of the mononucleated cells in peripheral blood that can generate both false-positive or negative results. ${ }^{4}$

The most recent method used for TB detection is molecular assay. The molecular method has a rapid turn-around time so it is preferable over culturing. A novel and advanced technique for TB molecular detection is the GeneXpert MTB/RIF assay. The assay is a qRT-PCR based molecular test that detects the presence of $M$. tuberculosis within less than 2 hours. ${ }^{4,25}$ This rapid assay was recommended by WHO in 2010 as the diagnostic test to detect TB and rifampicin resistance. ${ }^{1,28}$

GeneXpert MTB/RIF is an automatic cartridgebased assay that has many benefits. First, the closed amplification system can reduce the potency of cross-reactions. ${ }^{5}$ Second, the GeneXpert assay can yield information about rifampicin resistance coded in the rpoB gene. ${ }^{29}$ The rpoB gene is responsible for $96 \%$ of rifampicin resistance cases in $M$. tuberculosis infection. Rifampicin resistance is a key predictor for multidrug-resistant TB (MDR-TB), as most of the bacteria resistant to rifampicin are also resistant to isoniazid. ${ }^{5}$ Third, it can be used as a substitute for the microscopic test as it can detect the presence of the bacteria in both negative and positive smears. Fourth, the GeneXpert assay is able to recognize the presence of $M$. tuberculosis taken from different specimens. Lastly, the WHO asserted that the GeneXpert can be utilized as a preliminary test in suspected pulmonary TB patients. ${ }^{29}$

The GeneXpert MTB/RIF platform processes the specimens and analyzes them automatically. The platform consists of two components. That is, (i) a cartridge that contains sample reagent, PCR buffer, 
and qRT-PCR lipophilic reagent; and (ii) a GeneXpert instrument that controls the liquid inside the cartridge and performs a qRT-PCR analysis. The GeneXpert instrument amplifies the sequence of the rpoB gene that is specific to the genome of $M$. tuberculosis. The primer sequence of $M$. tuberculosis and rpoB-specific molecular beacons are modified to run a hemi-nested $P C R$ reaction so that it does not report the nontuberculous mycobacteria. It can also optimize the detection of rpoB mutations as the predictor of MDRTB. 5,25 In this platform, $M$. tuberculosis is detected using five overlapping molecular probes (A-E) in the $81 \mathrm{bp}$ region of the rpoB gene. The bacterium is identified if at least two of the five probes show positive signals with a cycle threshold $(\mathrm{Ct})$ of 38 cycles or less. A Ct is the number of cycles needed to obtain a positive result. The $\mathrm{Ct}$ values are classified into high ( $<16)$, medium (16$22)$, low (22-28), and very low (>28) categories. ${ }^{6}$

During the assay, the GeneXpert's sample reagent containing $\mathrm{NaOH}$ and isopropanol (3:1) is added to $0.5 \mathrm{ml}$ of sample. ${ }^{18,20}$ The addition of these reagents was aimed to dilute the sample, to reduce the infectiousness of the sample, and to inactivate the PCR inhibitors. ${ }^{17}$ The container consisting of the specimen is agitated twice within $15 \mathrm{~min}$ and incubated at room temperature. ${ }^{22,28}$ Then, $2 \mathrm{ml}$ of the mixture is inserted into the cartridge and the PCR is run automatically to detect $M$. tuberculosis and rifampicin resistance. ${ }^{17}$ In pulmonary TB, the assay can be performed using either raw sputum or pellet sputum. ${ }^{5,18}$

The GeneXpert assay may also produce falsepositive or false-negative results. False-positive results are often caused by false amplification target whereas false-negative results are often related to the problems with the sample, reagent, or the extent of PCR inhibitors. ${ }^{5}$ Error in sample processing can be minimized using Bacillus globigii spores as an internal control. The spores are inserted into the cartridge to ensure the lysis of $M$. tuberculosis and to detect PCR inhibitors..$^{28}$ The GeneXpert instrument requires stable electricity, an appropriate temperature $\left(\angle 30^{\circ} \mathrm{C}\right)$, and routine calibration of the cartridge module. ${ }^{16,18}$ Various diagnostic methods to detect M. tuberculosis and their availability in Indonesia are presented in Table 1.

\section{Samples for GeneXpert assay}

Sputum samples are required for diagnosing pulmonary TB, while for the diagnosis of EPTB the specimens can be obtained from pleural fluid, aspirate or tissues from lymph node, or CSF. ${ }^{30}$ For either pulmonary TB or EPTB, there are some specimens that can be subjected to GeneXpert assay. It is important to note, however, that specimens that are not of the respiratory system contain a low number of bacilli.

Table 1. Various laboratory procedures used to detect $M$. tuberculosis

\begin{tabular}{|c|c|c|c|}
\hline Test* & Sensitivity (\%) & Specificity (\%) & $\begin{array}{l}\text { Availability in } \\
\text { Indonesia }\end{array}$ \\
\hline NAAT-TB detection & 85 & 97 & Limited to some labs \\
\hline $\begin{array}{l}\text { NAAT-resistance markers (NAAT-R), for example, GeneXpert MTB/RIF } \\
\text { assay }\end{array}$ & $>92$ & $>99$ & $\begin{array}{l}\text { Limited to some } \\
\text { tertiary hospitals }\end{array}$ \\
\hline AFB microscopy & 70 & $\geq 90$ & Widely available \\
\hline \multicolumn{4}{|l|}{ Growth detection } \\
\hline Liquid & 90 & 99 & \multirow{2}{*}{$\begin{array}{l}\text { Limited to referral } \\
\text { hospitals or some labs }\end{array}$} \\
\hline Solid & 88 & 99 & \\
\hline $\begin{array}{l}\text { Identification of Mycobacterium tuberculosis complex by DNA probe/ } \\
\text { HPLC }\end{array}$ & 99 & 100 & $\begin{array}{l}\text { Limited to research labs } \\
\text { only }\end{array}$ \\
\hline First-line drug susceptibility testing (liquid medium) & $\geq 97$ & $\geq 97$ & $\begin{array}{l}\text { Limited to referral } \\
\text { hospitals or some labs }\end{array}$ \\
\hline \multicolumn{4}{|l|}{ Second-line and novel compound drug susceptibility testing } \\
\hline Liquid (broth-based) medium & $\geq 92$ & $\geq 97$ & \multirow{2}{*}{$\begin{array}{l}\text { Limited to referral } \\
\text { hospitals or some labs }\end{array}$} \\
\hline Solid (agar/egg-based) medium & $82-99$ & $92-100$ & \\
\hline
\end{tabular}

TB=tuberculosis; NAAT=nucleic acid amplification test; AFB=acid-fast bacilli; HPLC=high-performance liquid chromatography *Adapted from the diagnosis of TB in adults and children, Infectious Diseases Society of America guideline" 
The specimens for microbiology diagnostics should be collected from sterile locations. The sample reagent is added to the sample with the ratio of 2:1, except for CSF (ratio 3:1). The collected sample is then incubated at room temperature for $15 \mathrm{~min}$. Following incubation, the sample is inserted into the cartridge and tested using the GeneXpert instrument. ${ }^{13}$

Lymphadenitis TB is the most frequent form of EPTB. The sample can be obtained from the tissue or aspirated using fine needle biopsy from the lymph node. The use of fresh samples will yield a higher sensitivity than frozen samples. ${ }^{30}$ In pleural TB, the sample is taken from the pleural fluid whereas meningitis TB can be diagnosed using a CSF sample. The use of the GeneXpert assay has a high sensitivity to lymphadenitis TB, medium sensitivity to meningitis TB, and low sensitivity to pleural TB. ${ }^{19}$

It was also reported that there were different sensitivities of the GeneXpert assay that depend on the type of samples used. ${ }^{19}$ The sensitivities of the assay using tissue biopsy, fine needle aspirate, gastric aspirate, pus, CSF, and urine are $75 \%, 88.3 \%, 78.7 \%$, $87.3 \%, 85.7 \%$, and $87.5 \%$, respectively. Sensitivity values are lower using samples from pleural fluid (44.4\%), and other body fluids such as pericardium, peritoneum, and synovial fluid (50\%).

Sputum is the most frequently used sample for the diagnosis of pulmonary TB. Either raw sputum or pellet sputum can be used in the GeneXpert assay. The pellet sputum is raw sputum that is processed by liquefaction, decontamination using NALC/ $\mathrm{NaOH}$, and centrifugation. ${ }^{17}$ The raw sputum can be obtained by either spontaneous expectoration by the patient or after sputum induction. The types of sputum have different requirements for storage and transport. Pellet sputum can be stored at $2-8^{\circ} \mathrm{C}$ for up to 7 days, while raw sputum can be stored at a maximum of $35^{\circ} \mathrm{C}$ for 3 days and then moved to $2-8^{\circ} \mathrm{C}$ over the next 7 days. Previous studies reported that the sensitivities of GeneXpert using raw or pellet sputum are similar. ${ }^{17,23}$ Gastric aspirates can be subjected to the assay if the patient is old and cannot expel sputum effectively.

Another type of sample that can be used is fecal specimen. The required volume of the fecal specimen is $2 \mathrm{~cm}^{3}$. Ten milliliters of distilled water is required during the homogenization of the specimen using a vortex. ${ }^{31}$ The mixture of the fecal specimen and distilled water is incubated at room temperature for
$15 \mathrm{~min}$ and then centrifuged 3,000 for $20 \mathrm{~min}$. The sediment is then decontaminated using $10 \mathrm{ml}$ of $3 \%$ $\mathrm{NALC} / \mathrm{NaOH}$ for $15 \mathrm{~min}$ at room temperature. The sample is then mixed with $40 \mathrm{ml}$ of phosphate buffer (pH 6.8) and then centrifuged 3,00og for $20 \mathrm{~min}$. The sediment is then resuspended in $3 \mathrm{ml}$ of phosphate buffer and then inoculated into Ogawa medium and $M G I T^{T M}$. The remaining sample can be stored at $-80^{\circ} \mathrm{C}$ for 1 to 3 months. ${ }^{31}$

\section{Diagnosis of TB in Indonesia}

In Indonesia, the diagnosis of TB is based on clinical signs and symptoms, laboratory findings, and supporting examinations. The most common laboratory tests include direct microscopic examination, culturing using a solid medium (LJ) or liquid medium (MGIT ${ }^{\mathrm{TM}}$ ), and a rapid molecular test. The rapid molecular test can be performed by using GeneXpert MTB/RIF assay to diagnose $T B$, but not for treatment evaluation. The supporting examinations include radiology and histopathology. ${ }^{32-34}$

The Indonesian Ministry of Health developed a workflow for diagnosing TB. It is described as follows: First, a thorough clinical examination should be performed on adult patients with a productive cough of 2 weeks or more. The sputum should be taken three times for the microscopic evaluation of AFB. If any of the results in the microscopic test is positive, the patient is treated as TB positive. If the results of the microscopic test are negative but there is a strong clinical suspicion, the patient should be referred to a more advanced health service provider for chest $\mathrm{X}$-ray examination and/or other tests, such as rapid test or culturing. A suggestive $X$-ray result justifies TB treatment even when the results of the microscopic test are negative. In a situation where the patient cannot be referred, the patient can be treated with antibiotics and then reevaluated. Should there be a clinical improvement after antibiotics treatment; the patient would be considered as non-TB. If there is no improvement, the clinical assessment and sputum microscopic tests should be repeated. Drug susceptibility testing can be performed if the culture is identified as $M$. tuberculosis. In cases where the bacteria are resistant to rifampicin, the patient should be referred to health facilities that are able to treat MDR-TB. ${ }^{2}$

The diagnosis of TB in children is based on the history of contact, clinical examination, and 
supportive tests. AFB may be detected from microscopic testing of sputum samples or tissue biopsy. Culturing may also be performed but serological testing is not recommended by WHO. The use of GeneXpert MTB/RIF in children is limited because its sensitivity (48\%) is lower than that of culturing and clinical examination. In addition, a negative result of GeneXpert assay does not always mean that the child does not have TB. Other tests that may be helpful in diagnosing TB in children include radiology and TST. The Indonesian Ministry of Health developed a scoring system to diagnose TB in children. The scoring system is based on the history of TB contact, TST results, the presence of an undifferentiated fever for 2 weeks or more, a chronic cough for 3 weeks or more, cervical/axillary/inguinal lymphadenopathy, enlargement of bone or joint in waist/knee/finger, and the chest $\mathrm{X}$-ray result. ${ }^{34}$

Despite the available diagnostic methods in Indonesia, there are still a high number of TB cases that are currently unreported. To overcome this, a compulsory policy on notification and intense engagement with the public and private hospitals wherever many TB patients were being treated is recommended. In addition, the use of GeneXpert in a national TB prevalence survey could increase the detection of TB cases. Previously, the survey only consisted of using a cough of 2 weeks or more for screening and microscopy for diagnosis. After 2013-2014, more sensitive methods were used for the survey, there are screening using symptoms and $X$-ray results; and diagnosis by smear and culturing with the GeneXpert assay to confirm smear-positive specimens. As a result of active, intensive case finding and mandatory notification, TB detection has increased significantly since 2016 .

TB, as one of the major global problems, can be diagnosed using several methods such as culturing, microscopic examination, TST, IGRAs, and NAAT. At present, WHO recommends the use of GeneXpert, as the assay works rapidly and automatically thus TB detection can be increased. In Indonesia, the standard TB diagnosis method employs clinical examination and sputum microscopy that is supported by chest radiology. If the results of the sputum microscopy are negative, other tests can be performed such as culturing and NAAT.

Conflict of Interest

The authors affirm no conflict of interest in this study.
Acknowledgment

None.

Funding Sources

None.

\section{REFERENCES}

1. World Health Organization [Internet]. Global Tuberculosis Report 2018. Geneva: World Health Organization; 2018 [cited 2019 Apr 5]. Available from: https://www.who.int/tb/ publications/global_report/en/

2. Indonesian Ministry of Health. National Guidelines for Tuberculosis Control (Pedoman Nasional Pengendalian Tuberkulosis) 2014. Jakarta; 2014. p. 1-210.

3. Collins D, Hafidz F, Mustikawati D. The economic burden of tuberculosis in Indonesia. Int J Tuberc Lung Dis. 2017;21(9):104148.

4. Molicotti P, Bua A, Zanetti S. Cost-effectiveness in the diagnosis of tuberculosis: choices in developing countries. J Infect Dev Ctries. 2014;8(1):24-38.

5. Helb D, Jones M, Story E, Boehme C, Wallace E, Ho K, et al. Rapid detection of Mycobacterium tuberculosis and rifampin resistance by use of on-demand, near-patient technology. J Clin Microbiol. 2010;48(1):229-37.

6. Lawn SD, Nicol MP. Xpert ${ }^{\circledR}$ MTB/RIF assay: development, evaluation and implementation of a new rapid molecular diagnostic for tuberculosis and rifampicin resistance. Future Microbiol. 2011;6(9):1067-82.

7. Nikam C, Kazi M, Nair C, Jaggannath M, Manoj MM, Vinaya RV, et al. Evaluation of the Indian TrueNAT micro RT-PCR device with GeneXpert for case detection of pulmonary tuberculosis. Int J Mycobacteriol. 2014;3(3):205-10.

8. Yruela I, Contreras-Moreira B, Magalhães C, Osório NS, GonzaloAsensio J. Mycobacterium tuberculosis complex exhibits lineagespecific variations affecting protein ductility and epitope recognition. Genome Biol Evol. 2016;8(12):3751-64.

9. Goldman E, Green LH. Practical Handbook of Microbiology. Second Edition. Boca Raton: CRC Press; 2009. pp. 109-1.1

10. Centers for Disease Control and Prevention; National Center for HIV/AIDS, Viral Hepatitis, STD, TB Prevention - Division of Tuberculosis Elimination [Internet]. Core Curriculum on Tuberculosis: What the Clinician Should Know. Atlanta: Centers for Disease Control and Prevention; 2013 [cited 2018 Jan 15]. Available from: https://www.cdc.gov/tb/education/corecurr/ pdf/corecurr_all.pdf

11. Lewinsohn $\bar{D}$ M, Leonard MK, LoBue PA, Cohn DL, Daley CL, Desmond E, et al. Official American Thoracic Society/Infectious Diseases Society of America/Centers for Disease Control and Prevention Clinical Practice Guidelines: diagnosis of tuberculosis in adults and children. Clin Infect Dis. 2017;64(2:)111-5.

12. Nunes-Alves C, Booty MG, Carpenter SM, Jayaraman P, Rothchild AC, Behar SM. In search of a new paradigm for protective immunity to TB. Nat Rev Microbiol. 2014;12(4):289-99.

13. Pravin KN, Chourasia E. Use of GeneXpert assay for diagnosis of tuberculosis from body fluid specimens, a 2 years study. J Microbiol Biotechnol. 2016;1(1):000105.

14. Indonesian Ministry of Health. Indonesian Health Profile (Profil Kesehatan Indonesia) 2015. 2016. p. 403.

15. Garcia de Viedma D, Lorenzo G, Cardona PJ, Rodriguez NA, Gordillo S, Serrano MJ, et al. Association between the infectivity of Mycobacterium tuberculosis strains and their efficiency for extrarespiratory infection. J Infect Dis. 2005;192(12):2059-65.

16. Piatek AS, Van Cleeff $M$, Alexander $H$, Coggin $W L$, Rehr $M$, Van Kampen S, et al. GeneXpert for TB diagnosis: planned and purposeful implementation. Glob Health Sci Pract. 2013;1(1):1823.

17. Dharan NJ, Amisano D, Mboowa G, Ssengooba W, Blakemore 
R, Kubiak RW, et al. Improving the sensitivity of the Xpert MTB/ RIF assay on sputum pellets by decreasing the amount of added sample reagent: a laboratory and clinical evaluation. J Clin Microbiol. 2015;53(4):1258-63.

18. Steingart KR, Schiller I, Horne DJ, Pai M, Boehme CC, Dendukuri N. Xpert ${ }^{\circledR}$ MTB/RIF assay for pulmonary tuberculosis and rifampicin resistance in adults. Cochrane Database Syst Rev. 2014;(1):CDoo9593.

19. Lawn SD, Zumla Al. Diagnosis of extrapulmonary tuberculosis using the Xpert ${ }^{\circledR}$ MTB/RIF assay. Expert Rev Anti Infect Ther. 2012;10(6):631-5.

20. Agrawal M, Bajaj A, Bhatia V, Dutt S. Comparative study of GeneXpert with ZN stain and culture in samples of suspected pulmonary tuberculosis. J Clin Diagn Res. 2016;10(5):DC09-12.

21. Guenaoui K, Harir N, Ouardi A, Zeggai S, Sellam F, Bekri F, et al. Use of GeneXpert Mycobacterium tuberculosis/rifampicin for rapid detection of rifampicin resistant Mycobacterium tuberculosis strains of clinically suspected multi-drug resistance tuberculosis cases. Ann Transl Med. 2016;4(9):168.

22. Zeka AN, Tasbakan S, Cavusoglu C. Evaluation of the GeneXpert MTB/RIF assay for rapid diagnosis of tuberculosis and detection of rifampin resistance in pulmonary and extrapulmonary specimens. J Clin Microbiol. 2011;49(12):4138-41.

23. Ghariani A, Jaouadi T, Smaoui S, Mehiri E, Marouane C, Kammoun $S$, et al. Diagnosis of lymph node tuberculosis using the GeneXpert MTB/RIF in Tunisia. Int J Mycobacteriol. 2015;4(4):270-5.

24. Pang $\mathrm{Y}$, Su B, Zheng $\mathrm{H}$, Zhang $\mathrm{Z}$, Ma A, Wang $\mathrm{Y}$, et al. Factors associated with missed detection of Mycobacterium tuberculosis by automated BACTEC MGIT 960 system. Biomed Res Int. 2016;2016:5972021.

25. Maynard-Smith L, Larke N, Peters JA, Lawn SD. Diagnostic accuracy of the Xpert MTB/RIF assay for extrapulmonary and pulmonary tuberculosis when testing non-respiratory samples: a systematic review. BMC Infect Dis. 2014;14:709.
26. Duman N, Ersoy-Evans S, Karadağ O, Așçioğlu S, Sener B, Kiraz $\mathrm{S}$, et al. Screening for latent tuberculosis infection in psoriasis and psoriatic arthritis patients in tuberculosis-endemic country: a comparison of the QuantiFERON ${ }^{\oplus}$-TB Gold In-Tube test and tuberculin skin test. Int J Dermatol. 2014;53(10):1286-92.

27. Niguse S, Desta K, Gebremichael G, Gebrezgeaxier A, Getahun $M$, Kassa D. GuantiFERON-TB Gold In-tube test for the diagnosis of active and latent tuberculosis in selected health facilities of Addis Ababa, Ethiopia. BMC Res Notes. 2018;11(1):293.

28. Pandey S, Congdon J, McInnes B, Pop A, Coulter C. Evaluation of the GeneXpert MTB/RIF assay on extrapulmonary and respiratory samples other than sputum: a low burden country experience. Pathology. 2017;49(1):70-4.

29. Nurwidya F, Handayani D, Burhan E, Yunus F. Molecular diagnosis of tuberculosis. Chonnam Med J. 2018;54(1):1-9.

30. Denkinger CM, Schumacher SG, Boehme CC, Dendukuri N, Pai M, Steingart KR. Xpert MTB/RIF assay for the diagnosis of extrapulmonary tuberculosis: a systematic review and metaanalysis. Eur Respir J. 2014;44(2):435-46.

31. Kokuto H, Sasaki $\mathrm{Y}$, Yoshimatsu S, Mizuno K, Yi L, Mitrai S. Detection of Mycobacterium tuberculosis (MTB) in fecal specimens from adults diagnosed with pulmonary tuberculosis using the Xpert MTB/rifampicin test. Open Forum Infect Dis. 2015;2(2):ofv074.

32. Indonesian Minister of Health. The Minister of Health Rules No. 67 the Year 2016 about Management of Tuberculosis (Peraturan Menteri Kesehatan Nomor 67 Tahun 2016 tentang Penanggulangan Tuberkulosis). Jakarta; 2016. pp. 1-163.

33. Indonesian Ministry of Health. National Guidelines of Medical Service for Management of Tuberculosis (Pedoman Nasional Pelayanan Kedokteran Tata Laksana Tuberkulosis). Jakarta; 2013. p. 1-210.

34. Indonesian Ministry of Health. Technical Guidelines about Management of Tuberculosis in Children (Petunjuk Teknis Manajemen dan Tatalaksana TB Anak). Jakarta; 2016. p. 1-98. 